\title{
A. Summary
}

DE92 005523

J. Craig Venter, National Institute of Neurological Disorders and Stroke, has begun to identify genes expressed in the human brain by partially sequencing cDNA clones (Adams et al., Science 252:1651-1656, 1991). We are collaborating with the Venter group and using their sequence data to develop methods for rapid localization of newly identified cDNAs to human chromosomes. We are applying the ABI automated DNA sequencer to the analysis of fluorescently-tagged PCR products for assigning sequences to individual human chromosomes. The steps in our mapping protocol are (1) to design PCR primers from the Venter laboratory-generated sequence data, (2) to test the primers for specific amplification from human genomic DNA, (3) to use the primers for PCR amplification from a somatic cell hybrid cell mapping panel, (4) to determine the presence or absence of the specific amplification products from each cell line DNA by electrophoretic analysis using the ABI sequencer, and (5) to analyze the pattern of amplification results from the hybrid panel to identify the chromosomal origin of the cDNA sequence. We have demonstrated the principle by mapping 12 sequences or "Expressed Sequence Tags" (ESTs), providing primer sequence data for subsequent subchromosomal localizations. We will now concentrate on developing methodology to allow multislexing the amplification reactions and analysis of the reaction products, to achieve a high throughput with a minimum allocation of resources. This project will generate a data set from which to evaluate strategies to identify functional primer sequences from cDNA sequence data.

\section{B. Methods}

1. Primer design. We have been using the PRIMERS software (Lowe et al., 1990) to identify potential primers from the sequence files supplied by the Venter laboratory. A batch of $\mathrm{CDNA}$ sequence files is analyzed under narrowly defined parameters ( $50 \% \mathrm{GC}$, Tm of amplified fragment $78-81^{\circ} \mathrm{C}$, amplified fragment size $100-150 \mathrm{bp}$ ), and the oligonucleotides identified are used to test for amplification from human, hamster, or mouse genomic DNA.

2. Amplification and determination of fragment size. So far, one of each oligonucleotide primer pair was synthesized with 5' Aminolink II and labeled with a fluorescent dye using a procedure provided by Applied Biosystems, Inc. Template DNA (50 $\mathrm{ng}$ ) was amplified in the presence of $80 \mathrm{ng}$ of each primer in a total volume of $15 \mu \mathrm{l}$. Other components were as described in the Perkin Elmer Cetus GeneAmp Kit protocol (P/N N8010043 ). The temperature profile consisted of a $95^{\circ} \mathrm{C}$ denaturation step for $5 \mathrm{~min} ; 25$ cycles of $94^{\circ} \mathrm{C}$ for $1.4 \mathrm{~min}, 55^{\circ} \mathrm{C}$ for $2 \mathrm{~min}, 72^{\circ} \mathrm{C}$ for $2 \mathrm{~min}$, and a final $10 \mathrm{~min}$ incubation at $72^{\circ} \mathrm{C}$ to complete product extension. One $\mu \mathrm{l}$ of the PCR product was pooled with a fluorescentlylabelled internal lane size standard (PGEM3Z sequencing ladder with only ddTTP chain termination products). This mixture was ethanol-precipitated and ie-suspended in $5 \mu \mathrm{l}$ of deionized formamide. Saniple was denatured at $95^{\circ} \mathrm{C}$ for 2 minutes before loading onto a $6 \%$ polyacrylamide denaturing gel $(8 \mathrm{M}$ urea). Data from the electrophoretic run were collected on an ABI 370A automated sequencer.

During this period, hardware and software were obtained to upgrade the instrumentation to a 373A. Data collection is currently done in parallel because of the lack of software for the 373A to determine fragment sizes. The 373A software (GeneScan) should be installed in November, 1991.
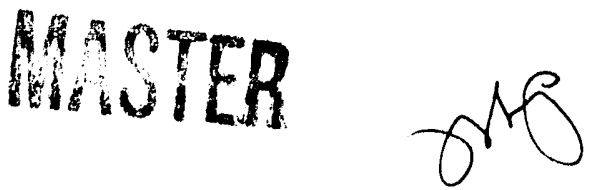
3. Chromosome assignment. Primer pairs were tested for amplification of a product from human genomic DNA of the size predicted from the CDNA sequence and distinguishable from mouse or Chinese hamster. Primers meeting this criterion were then tested on DNA from human/rodent somatic cell hybrids obtained from the NIGMS Human Genetic Mutant Cell Repository (NIGMS panel \#1) and/or from the BIOS Corporation (PCRable DNA).

Sequences were assigned to a chromosome when the discordancy va' was less than $9 \%$. Chromosomes reported as being present in fewer than $10 \%$ of metap ises were not included in the discordancy analysis.

\section{Results}

1. Representative throughput. The following table summarizes the mapping process for a set of files received from the Venter laboratory. Of 36 sequences analyzed, 13 could be used to predict primers according to the criteria described in Methods. So far 10 of these have been tested, with 6 resulting in unambiguous chromosome assignment.

\section{Table 1}

Total files in batch:

Total files giving at least 1 possible primer pair:

Total primer pairs tested:

Total primer pairs giving amplification in human distinct from rodent:

Total unambiguously mapped:

2. Chromosome assignment. A subset of primers successful in mapping human sequences is given in Table 2. Additional details about fragments detected in human and rodent cells (MMU = Mus musculus, $\mathrm{CHO}=$ hamster) cells are given in Table 3 . The results of the discordancy analyses are summarized in Table 4. Three sequences were assigned to a chromosome in spite of a single discordant result. Two discordancies resulted from the inability to detect a fragment when the chromosome was reported to be present, one resulted from the detection of a weak band, possibly of a smaller size, which was not detected in any other reaction.

\section{DISCLAIMER}

\footnotetext{
This report was prepared as an account of work sponsored by an agency of the United States Government. Neither the United States Government nor any agency thereof, nor any of their employees, makes any warranty, express or implied, or assumes any legal liability or responsibility for the accuracy, completeness, or usefulness of any information, apparatus, product, or process disclosed, or represents that its use would not infringe privately owned rights. Reference herein to any specific commercial product, process, or service by trade name, trademark, manufacturer, or otherwise does not necessarily constitute or imply its endorsement, recommendation, or favoring by the United States Government or any agency thereof. The views and opinions of authors expressed herein do not necessarily state or reflect those of the United States Government or any agency thereof.
} 


\section{Table 2}

$\begin{array}{llllll}\text { ATCC\# } & \text { EST } & \text { NAME } & \text { PRIMERS }\left(5^{\prime}->3^{\prime}\right) & \text { (bp) } & \text { CH } \\ 61986 & \text { EST104 } & \text { HHCG36 } & \begin{array}{l}\text { AL2-CAGATCAATACATCCTCTGGGG } \\ \text { CTGTGCAGTGGTGAGTAAAAGG }\end{array} & 181 & 5 \\ 61906 & \text { EST109 } & \text { HHCG44 } & \begin{array}{l}\text { AL2-CTAACCACAACCCACACATTGG } \\ \text { CCTCAGCACAAGAGAAGAATGG }\end{array} & 144 & 11 \\ 61922 & \text { EST113 } & \text { HHCG70 } & \begin{array}{l}\text { AL2-TCGGAGAAGTTCAGTTTCTGG } \\ \text { GTTAAAAGCTGTTAGACGGGGC }\end{array} & 159 & 20 \\ 37920 & \text { EST94 } & \text { HHCE15 } & \begin{array}{l}\text { AL2-GCAGGATGTCAGTCTTTGAGG } \\ \text { AGCACACATTATCTACCACGGC }\end{array} & 137 & 3 \\ 61830 & \text { EST38 } & \text { HHCA23RZ } & \begin{array}{l}\text { AL2-GGAAGTACAGGATTGGC } \\ \text { TTAGAGATGGGATGATGCCG }\end{array} & 150 & 4\end{array}$

\section{Table 3}

\begin{tabular}{lllllrl}
\multicolumn{1}{l}{ ATCC\# EST } & NAME & $\mathbf{E}^{1}$ & $\mathrm{O}^{2}$ & $\mathbf{C H}$ & NOTES \\
61896 & EST00104 & HHCG36 & 181 & 183 & 5 & \\
61906 & EST00109 & HHCG44 & 144 & 147 & 11 & CHO band approximately 380 bp \\
61922 & EST00113 & HHCG70 & 159 & 148 & 20 & \\
37920 & EST00094 & HHCE15 & 137 & 141 & 3 & \\
61830 & EST00038 & HHCA23RZ & 150 & 151 & 4 & MMU band approximately 400 bp \\
& HHCF44F & 170 & 173 & 1 & \\
& HHCMC10F & 133 & 135 & 5 & MMU band 145 bp strong; \\
& & & & & & \\
& HHCMC37F & 122 & 123 & 4 & MMU band 285 bp weak \\
& HHCMC78F & 139 & 143 & 3 & \\
& HHCMC82F & 143 & 450 & $X$ & MMU band 445 bp, >600 bp \\
& HHCMC70F & 147 & 161 & 7 &
\end{tabular}

'Expected fragment size in nucleotides ${ }^{2}$ Observed fragment size in nucleotides 


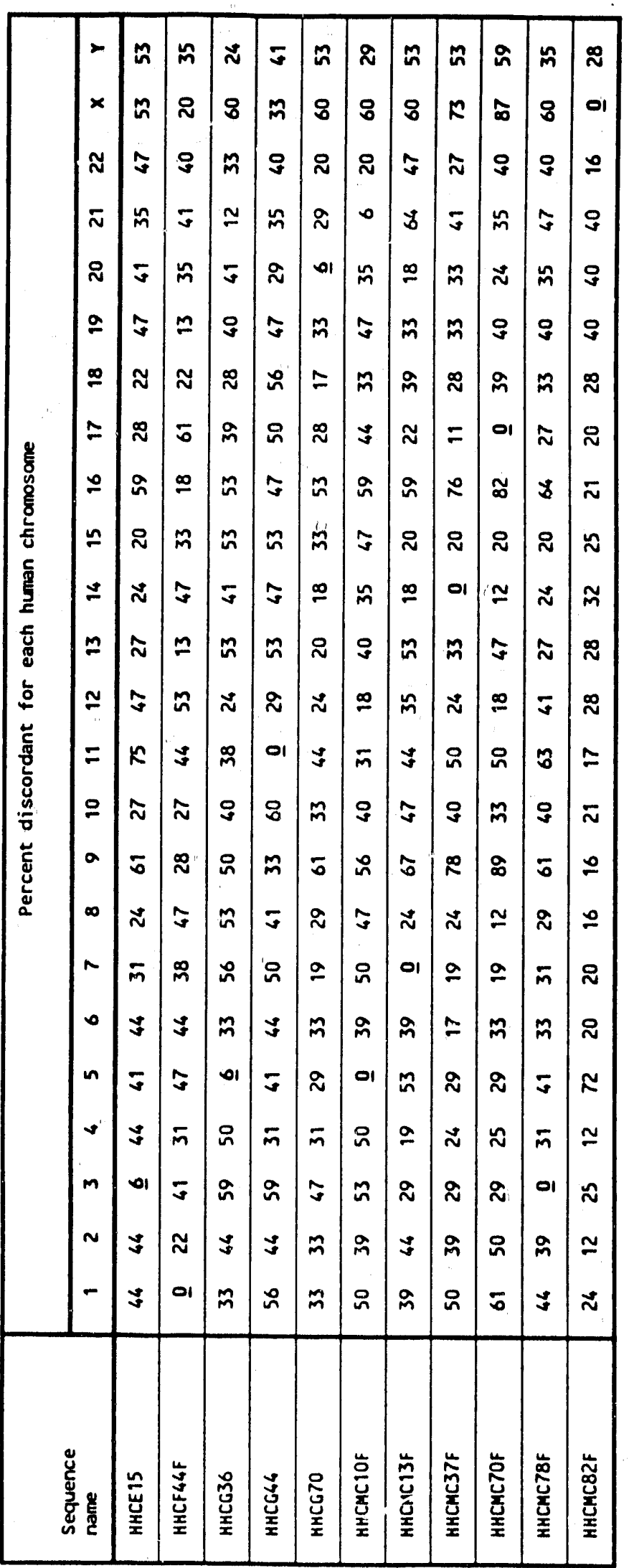



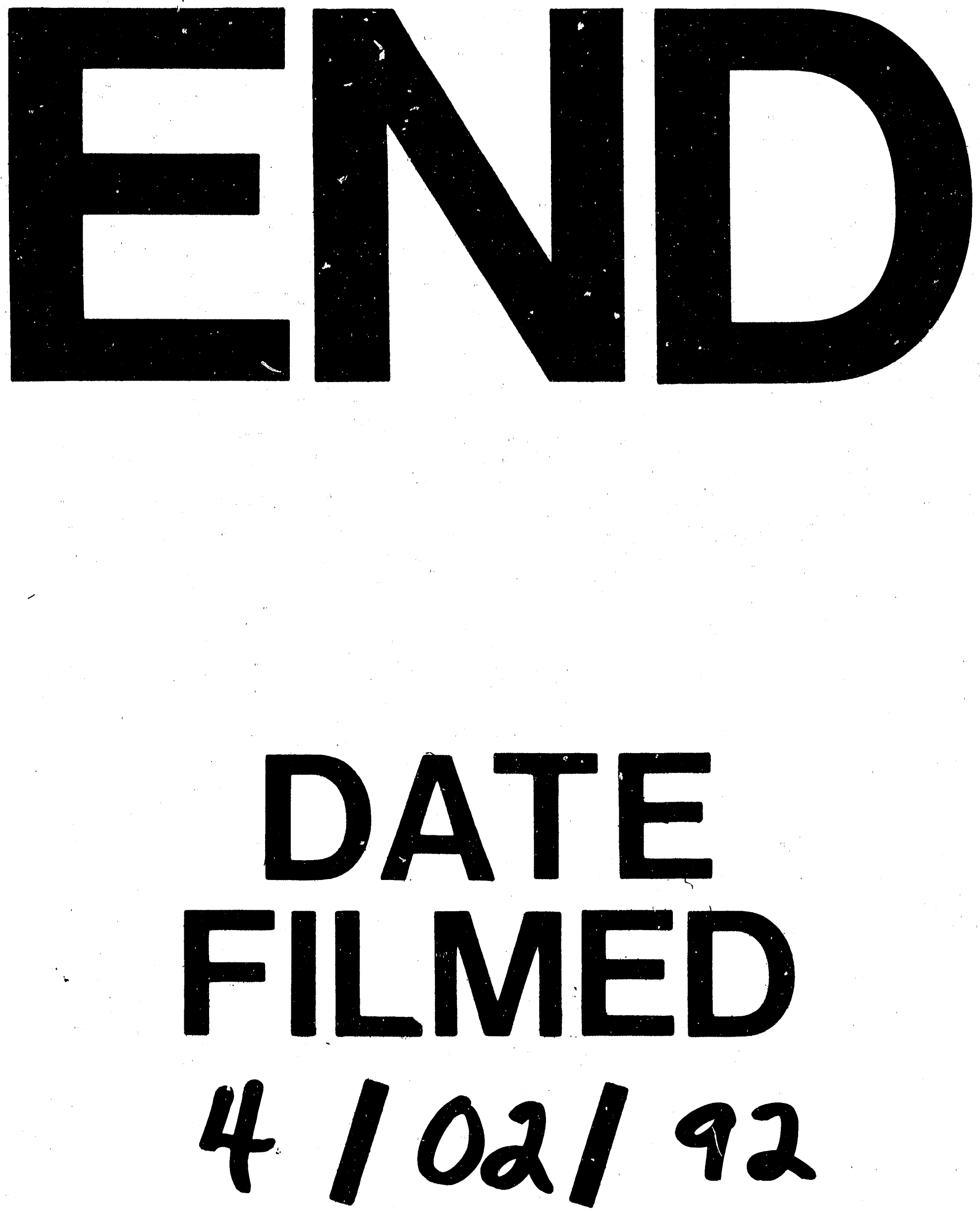
